\section{Response: Re: Effects of Implementing a Comprehensive Opioid Reduction Protocol on Overall Opioid Prescribing Among Patients with Chronic, Non-Cancer Pain in a Rural Family Medicine Clinic: A Controlled Crossover Trial}

To the Editor: We appreciate Dr. Gase's drawing attention to the patient's experience during opioid reduction. We agree with the importance of functional assessment, longitudinal followup, * and treating the whole person. However, we believe that Dr. Gase, and the medical community in general, have not gone nearly far enough in our advocacy for patients with chronic noncancer pain. We would like to illustrate with 2 patients from our original intervention group who we continue to see clinically.

Betty is a 47-year old female ${ }^{\dagger}$ who was in our original intervention group. When she first came to us, she was on 438 Morphine Milligram Equivalents (MME) and Xanax TID. In the context of a trusted family medicine relationship, she talked about her childhood experiences. At age 8 years she frequently stood between her stepfather and her 2 younger brothers, taking his violent blows intended for them. Her mother stood by encouraging the stepfather to "teach them a lesson." At night, Betty would lie awake in bed, hearing her mother drive away to work the night shift and then her father's footsteps coming down the hall toward her bedroom.

At a recent appointment, Betty was excited to share a tape recording of her courageously confronting her now elderly stepfather for the first time about the truth of his physical and sexual violence. Betty is off benzodiazepine and is on 22.5 MME.

Jean is a 43 -year old female ${ }^{\dagger}$ who was in our original intervention group. When she first came to us she was on $180 \mathrm{MME}$. As trust developed in our primary care relationship, she began to tell us about how her uncle would "spank" her. He instructed her to pull her pants and underwear down to her knees, bend over and grab her ankles, while he hit her repeatedly on her exposed bottom and perineum. This happened until she left home at age 17 years.

At a recent appointment, Jean shared with us her joy about spending a beautiful fall day shopping and going out for dinner with 3 girlfriends. Other than receiving 5 Tylenol \# 3 after foot surgery, Jean has been completely off opioids for more than a year.

If we as a medical community really want to address the opioid crisis, we need to move beyond passing out self-report forms of pain and function and start passing out the Adverse Childhood Experiences form. ${ }^{1}$ We need to recognize that "the body keeps the score" 2 " and that many of our patients with chronic noncancer pain are using opioids to anesthetize real psychophysiological pain that has resulted from childhood neglect and trauma. 3,4
Family medicine physicians are in the position to take the lead in promoting evidence-based, trauma-informed therapies $^{5}$ in our communities. We also must advocate for infant-parent mental health services in our communities if we hope to exorcise the "ghosts in the nursery" that perpetuate the cycles of neglect and abuse.

Much like the game, "whack-a-mole," our society has tried for decades to suppress the addiction crisis $d u$ jour, only to have another pop up in its place. Family medicine doctors need to take the lead in addressing the all-toofrequent common denominator of our patients' chronic pain and chemical dependence.... the reality that we live in a society that neglects and abuses its children.

*At 1-year followup, we continue to provide primary care for $75 \%$ of the patients who were in our original control group. The current MME for our original intervention group is significantly lower now (11.7 MME) than it was at the end of the intervention period (29.7 MME) $(P=.01$; CI, 6.1-17).

${ }^{\dagger}$ Name and demographics changed for patient confidentiality.

$$
\begin{array}{r}
\text { Matthew A. Stack, DHA, MA, MS } \\
\text { Michigan State University/Mid-Michigan Gratiot } \\
\text { Family Medicine Residency } \\
\text { Alma, MI } \\
\text { matthew.stack@midmichigan.org }
\end{array}
$$

To see this article online, please go to: http://jabfm.org/content/ 34/1/244.full.

\section{References}

1. Felitti V, Anda R, Nordenberg D, et al. Relationship of childhood abuse and household dysfunction to many of the leading causes of death in adults. Am J Prevent Med 1998;14:245-58.

2. Van der Kolk B. The body keeps the score: brain, mind and body in the healing of trauma. London, UK: Penguin Books; 2015.

3. Abbass A, Schubiner S. Hidden from view: a clinician's guide to psychophysiological disorders. Medford, MA: Psychophysiologic Press; 2018.

4. Derefinko K, Garcia F, Talley K, et al. Adverse childhood experiences predict opioid relapse during treatment among rural adults. Addict Behav 2019;96:171-4.

5. Watkins LE, Sprang KR, Rothbaum BO. Treating PTSD: a review of evidence-based psychotherapy interventions. Front Behav Neurosci 2018;12:258.

6. Fraiberg S, Adelson E, Shapiro V. Ghosts in the nursery: a psychoanalytical approach to the problems of impaired infant-maternal relationships. J Am Acad Child Psychiatry 1975;14:387-421.

doi: 10.3122/jabfm.2021.01.200603 